\title{
Scaling of sensitivity to torque
}

LEROY A. STONE AND DAVID R. SKEEN THE UNIVERSITY OF NORTH DAKOTA

Two groups of Ss judged a sequence of torque presentations with instructions that they judge heaviness using category scale and magnitude estimation procedures. Power functions appropriately described the psychophysical relationship between the subjective estimations and $\mathrm{g}-\mathrm{cm}$. Subjective torque was classified as a prothetic judgment continuum based on two criteria.

Sensitivity to torque, the turning moment of a tangential effort, was recently shown (Woodruff \& Helson, 1965) with two different psychophysical methods, to behave in a manner similar to sensitivity to tactile pressure. Using an 11-point comparative rating scale, they found negatively accelerated curves for low values of the standard and a positively accelerated curve when there was a high value standard; using the method of constant stimulus differences, they found the Weber fraction for "heavier" judgments to be similar to those reported for weight judgments.

Research results have shown that for prothetic continua (where discrimination presumably involves an additive process, as opposed to metathetic, or substitutive, continua), subjective magnitude grows as a power function of stimulus intensity (Stevens, 1957). The prothetic continuum of heaviness (judged from lifted weights) has been extensively studied by psychologists for more than 100 years. Stevens \& Galanter (1957), using data from several independent investigations, found, as a first order approximation, that subjective weight could be regarded as a power function of physical weight (exponent $\simeq 1.45$ ).

The present study was designed to examine whether the ratio scale of torque, determined by the method of magnitude estimation, has a power function exponent similar to that reported for lifted weights. Also examined was whether such a subjective magnitude behaves prothetically, i.e., according to the classification criteria prescribed by Stevens (1957).

\section{Procedure}

The apparatus 2 used consisted of two stimulus weights which were manipulated (hung) in various set positions on a rod so as to produce various torque values. This apparatus has been described in detail elsewhere (Woodruff \& Helson, 1965). The only modification was that different hanging block weights were used: with Group $1(N=9$, naive male undergraduates), the hanging block weighed $121.4 \mathrm{~g}$ and when hung on nine different distances $(9.70,10.95$, $12.20,13.45,14.70,15.95,17.20,18.45$, and $19.70 \mathrm{~cm}$ ) from the fulcrum resulted in a like number of dif- ferent torque stimulus presentations $(1180,1334,1486$, $1638,1790,1943,2095,2247$, and $2399 \mathrm{~g}-\mathrm{cm})$; with Group $2(N=7$, naive male undergraduates), the block weighed $149.2 \mathrm{~g}$ and when hung on the same positions produced nine different torque stimuli (1448, 1634, 1821, 2008, 2195, 2381, 2568, 2755, and $2941 \mathrm{~g}-\mathrm{cm}$ ).

The stimulus rod was presented to the Ss of both groups enclosed in a cardboard box, $20 \times 12 \times 11$ in. The back had been cut out so that the stimulus weights could be adjusted by the $E$. The front was covered by a black velvet cloth which had a central vertical slit (6.75 in. long) cut in it. The S's end of the rod protruded from the front of the box through the slit. Except for the cloth, all parts of the apparatus were painted flat black. All Ss were asked to make magnitude estimations (no assigned modulus) and category scale judgments regarding the "heaviness" of the different torque stimuli. The category scale ranged from 1 (equal to the lightest stimulus) to 7 (equal to the heaviest stimulus). Half of the Ss made their category judgments before making magnitude estimations. For each $S$ the order of the stimulus presentations was randomly determined.

Results

The groups' category scale values for each stimulus was the mean category number; that for the magnitude scale was the geometrical mean of the assigned numbers. The groups' magnitude scales (for heaviness) were graphed against the stimulus variable (torque in $\mathrm{g}-\mathrm{cm}$ ) in $\log -\log$ coordinates. It can be seen (Fig. 1) that straight lines offer reasonably good approximations to the data trends; i.e., power functions approximately describe the psychophysical

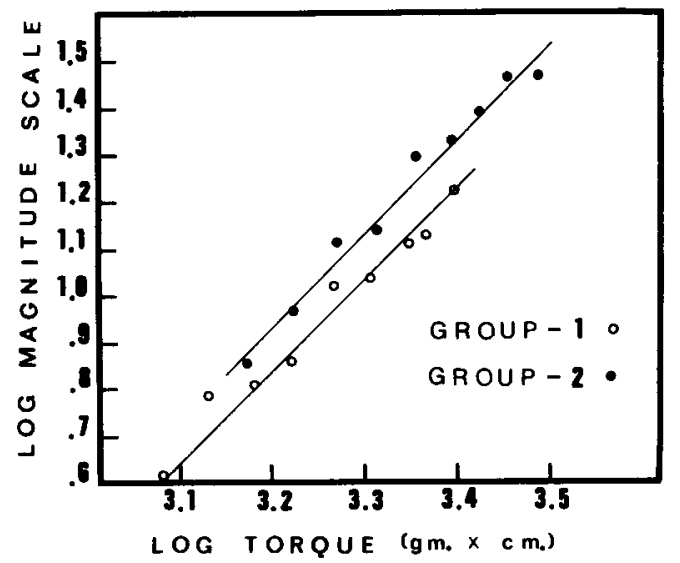

Fig. 1. The relation (for Groups 1 and 2) between log magnitude scale and $\log$ torque $(\mathrm{g} \mathrm{x} \mathrm{cm})$. 


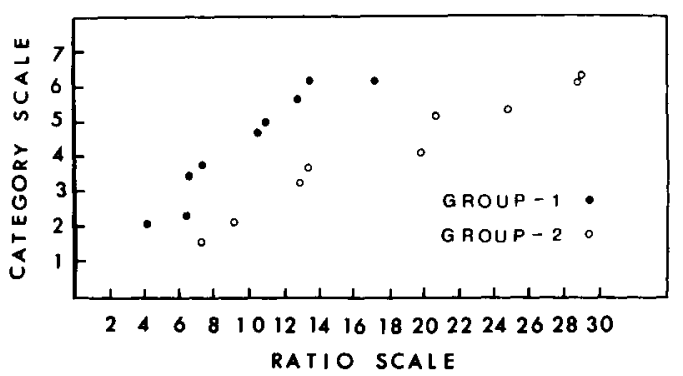

Fig. 2. Relationships between the category and magnitude scales for Groups 1 and 2.

relationships. For Groups 1 and 2 the slopes (power function exponents) were quite similar, 2.06 and 1.89 , respectively.

When the groups' category scales (on the ordinate) were graphed (see Fig. 2) against the magnitude scales (on the abscissa) the relations could be described as "slightly concave downward," which would suggest a prothetic continuum classification. Another characteristic which has been specified (Stevens, 1957) for prothetic continua is that variability, in subjective unit measurement, grows as a linear function of subjective magnitude. For each group, quartile deviations (for the magnitude estimations) were computed for each stimulus. Product moment correlations were computed between this variability measure and the magnitude scale. For Groups 1 and 2 these correlations were .93 (df $=7, p<.01)$ and $.42(\mathrm{df}=7$, $p>.10)$, the average $r$ being $.78(p<.05)$. Such a relationship would support the suggestion that judgmental variability, with respect to magnitude estimation, increases with subjective magnitude, indicative of prothetic continua.

\section{Discussion}

The classification of subjective torque as a prothetic judgment continuum would seem to be warranted based on the results and the criteria suggested by Stevens (1957). The particular power function ex- ponents seen for this sensory dimension appear to be larger than those described for heaviness of lifted weights (Stevens \& Galanter, 1957). It is mentioned by Woodruff \& Helson (1965, pp. 276-277) that "Torque involving not only psychological pressure but also resistance to movement, hence a greater kinesthetic component than is usually found in lifted-weight stimulation, per se." These kinds of additional kinesthetic components might be expected to increase sensory sensitivity which would show in the form of larger (than with lifted weights) power function exponents. There have been power function exponents reported for subjective weight which are most similar to the ones we have described for torque sensitivity. Stevens \& Galanter (1957) report an exponent of 2.07 for subjective weight based on data from the Harper \& Stevens (1948) experiment, and they also cite the unpublished results of J. E. Karlin, who described such an exponent being approximately 2.0.

Consistent with what was observed in the Woodruff \& Helson (1965) experiment, it was also noted that, in the present investigation, arm, finger, and wrist movements were employed by Ss. It may be that sensitivity to torque varies depending upon which movements are used when estimating or judging torque.

\section{References}

HARPER, R. S., \& STEVENS, S. S. A psychological scale of weight and a formula for its derivation. Amer. J. Psychol, 1948, 61, 343-351. STEVENS, S. S. On the psychophysical law. Psychol Rev., 1957, 64, 153-181.

STEVENS, S. S., \& GALANTER, E. H. Ratio scales and category scales for a dozen perceptual continua. J. exp. Psychol., 1957, 54, 377-411. WOODRUFF, B., \& HELSON, H. Torque: a new dimension in tactilekinesthetic sensitivity. Amer. J. Psychol, 1965, 78, 271-277.

Note

1. This research was supported by a Public Health Service Fellowship (1-F3-MH-12,312-01) from the National Institute of Mental Health to L. A. Stone and by a grant from the University Committee on Research, The University of North Dakota.

2. The authors thank Professor Helson for loaning part of the apparatus used. 